Available online at http://jddtonline.info

RESEARCHARTICLE

\title{
WOUND HEALING POTENTIAL OF METHANOLIC EXTRACT OF TRIBULUS TERRESTRIS L. FRUITS
}

\author{
Javed Akhtar Ansari ${ }^{1}$, Shafique Ahmad*², Mohd. Jamil' ${ }^{2}$, Qamruzzama ${ }^{3}$ \\ ${ }^{1}$ MESCO College of Pharmacy, 13-5-741, MEC, Mustaeedpura, Karwan Road, Hyderabad-500 006, India \\ ${ }^{2}$ Faculty of Pharmacy, Jamia Hamdard, New Delhi-110062 \\ ${ }^{3}$ Department of Pharmacology, Annamalai University, Annamalai Nagar, India-608002 \\ *Corresponding author's Email ID: shafiquepharma@gmail.com
}

Received 08 Oct 2012; Review Completed 30 Oct 2012; Accepted 01 Nov 2012, Available online 15 Nov 2012

\begin{abstract}
The main objective of the present investigation is to evaluate the wound healing potential of methanolic extract of Tribulus terrestris L. (TT) fruits on Wistar rats. Wound healing (i.e. analgesic and anti-inflammatory) potential of the methanolic extract of the TT fruits at doses of 50,100\& $200 \mathrm{mg} / \mathrm{kg}$ was evaluated against the standard drug indomethacin at a dose of 20 $\mathrm{mg} / \mathrm{kg}$, p.o. Adult Wistar rats of either sex of six numbers in each group was undertaken for study and evaluated by acetic acid-induced writhing, hot plate reaction time, carrageenan-induced hind paw edema and safety test on gastric mucosa method. Methanolic extract of TT showed anti-nociceptive effect in acetic acid-induced writhing characterized by a significant decrease in the number of writhings in rats $(p<0.01)$. In hot plate test, TT showed nociceptive reaction towards thermal stimuli in rats and a significant increase in the reaction time was observed $(p<0.01)$. The test drug significantly inhibited the carrageenan-induced hind paw edema in rats that is indicative of the anti-inflammatory effect of TT $(p<0.01)$. However, no gastric lesions were observed in TT treated rats indicating the safety of test drug. The methanolic extract of TT showed significant wound healing potential in different animal models.

Keywords: analgesic, anti-inflammatory, indomethacin, gastric mucosa.
\end{abstract}

\section{INTRODUCTION}

The prevalence of chronic wounds in the community was mentioned as 4.5 per 1000 population whereas that of acute wounds is nearly double at 10.5 per 1000 population ${ }^{1}$. Wounds may happen due to physical, chemical or microbial agents in life ${ }^{2}$. Healing is a complex intricate process occurred in response to an injury that restores the function and integrity of damaged tissues ${ }^{3}$. Healing process can be broadly classified into three stages, inflammatory phase, proliferative phase and lastly the remodeling phase which determines the strength and appearance of the healed tissue ${ }^{4}$. Healing of a chronic wound requires care that is patient centered, holistic, interdisciplinary and should be cost effective and evidence based '. No substantial progress has been made in achieving a permanent cure of inflammation and wounds. The search of screening and development of drugs for wound healing is an everlasting problem. There is much hope of finding anti-inflammatory drugs from native plants, as these are still used in therapeutics despite the progress made in conventional chemistry and pharmacology for producing effective drugs ${ }^{5}$.

The practice of plants, plant extracts or plant-derived pure chemicals to manage disease become a therapeutic modality, which has stood the test of time. As assumed by the World Health Organization (WHO), about threequarters of the world population depends upon traditional remedies (mainly herbs) for the health care of its people. The traditional medicines also some time called as, herbal or natural medicine existed in one way or another in different cultures/civilizations, such as Egyptians, Western, Chinese, Kampo (Japan) and Greco-Arab or Unani/Tibb (South Asia) ${ }^{6,7}$.
Tribulus terrestris L. (TT; Zygophyllaceae), also known as puncture vine or small caltrops has immense importance in oriental medicine because they are used as an aphrodisiac, diuretic and anthelmintic, as well as to treat coughs and kidney failure ${ }^{8}$. TT reported to have antimicrobial, antihypertension, diuretic, antiacetylcholine, haemolytic activity, to stimulate spermatogenesis, libido and antitumor activity and effects on cardiovascular system ${ }^{9}$. Plants TT have 10 to $60 \mathrm{~cm}$ high, annual herb, with pinnate leaves and yellow flowers 10. The plant can be found in arid climate regions around the world as in southern USA, Mexico, Spain, Bulgaria, India, and China ${ }^{11}$. A number of natural products, plant products which are composed of active principles, like triterpenes, alkaloids, flavonoids and biomolecules have been reported to promote the process of wound healing ${ }^{12-}$ 14. By employing certain herbs which possess antiseptic, astringent, anti-inflammatory, antimicrobial, antioxidant and bio-stimulatory properties can improve the rate of wound healing ${ }^{15,16}$. Literature survey reveals that TT is rich in tannins and phenolic content and exhibits high antioxidant activity ${ }^{17}$. This can be the basis for the medicinal properties of the plant TT. Considering this observation, we conducted preliminary pharmacological investigations for wound healing properties of TT.

Thus, during the past decades many researchers have focused on medicinal plants with fewer side-effects for patients to develop anti-inflammatory and analgesic drugs. The present study was undertaken to investigate the wound healing potential of TT fruits in different animal models. 


\section{MATERIAL AND METHODS}

\section{Plant}

The fruits of TT were collected from Chidambaram, Cuddalore, Tamil Nadu, India. The plant was identified and authenticated by Prof. Dr. R. Selvaraj, Chief Botanist, Department of Botany, Annamalai University, Annamalai Nagar Chidambaram, Cuddalore, Tamil Nadu, India. A voucher specimen has been kept at the herbarium of the University.

\section{Preparation of extract}

The fruits of TT were dried in shade, powdered and passed through a 40-mesh sieve. Dried powder (500 g) was taken and subjected to successive extraction with petroleum ether, chloroform, methanol and water in soxhlet apparatus. The extracts were concentrated to dry residue by distillation (temperature $60{ }^{\circ} \mathrm{C}$ without vacuum) and dried completely in desiccators and weighed. The yield of the methanolic extract of TT was $19.5 \% \mathrm{w} / \mathrm{w}$. The extract of TT was freeze dried and stored at $-80^{\circ} \mathrm{C}$ until further use. The dried mass (yield=50.2 g) was diluted with normal saline and used in experiments.

\section{Preliminary phytochemical screening}

Petroleum ether, chloroform, methanolic and aqueous extracts of TT was subjected to preliminary phytochemical screening for their presence or absence of active constituents utilizing standard method of analyses 18

\section{Drugs and chemicals}

Carrageenan and indomethacin were procured from Sigma-Aldrich, St. Louis, MO, USA. Acetic acid was procured from Pure Chem. Ltd., India.

\section{Preparation of methanolic extract of TT fruits}

The dried plant material (100 g) TT fruits were extracted three times by refluxing with distilled water for $8 \mathrm{hrs}$ and the filtered extract was evaporated on a water bath to get a viscous methanolic extract.

\section{Experimental animals}

The study was conducted after obtaining institutional ethical committee clearance (160/1999/CPCSEA). Wistar rats (100-150 g; 4-6 weeks old, either sex) were maintained under controlled conditions of light $(12 \mathrm{~h} / 12$ $\mathrm{h})$, temperature $\left(26 \pm 2{ }^{\circ} \mathrm{C}\right)$ and relative humidity $(44-56 \%)$ for one week before and during the experiments. The animals had access to standard laboratory feed (Gold Mohur, Hindustan Lever Ltd., Mumbai, India) and water ad libitum.

\section{Analgesic activity}

\section{Acetic acid-induced writhing test}

Analgesic activity was assessed by abdominal writhing test using acetic acid ${ }^{19}$. The animals were divided into six groups ( $\mathrm{n}=6$ each) viz.: group I- acetic acid control (normal saline, $10 \mathrm{ml} / \mathrm{kg}$, p.o.); group II- indomethacin solution (20 mg/kg, p.o.); group III- TT-I (50 mg/kg, p.o.); group IV- TT-II (100 mg/kg, p.o.) \& group V- TT-III (200 $\mathrm{mg} / \mathrm{kg}$, p.o.).
In the writhing test, $0.2 \mathrm{ml}$ of $0.6 \%$ acetic acid solution was injected intraperitoneally and the number of writhes were counted starting $5 \mathrm{~min}$ after injection for a period of 20 minutes.

\section{Hot plate reaction time}

Analgesic activity was assessed by hot plate latency assay 19 . The animals were divided into six groups $(n=6$ each). The animals were divided into six groups ( $n=6$ each) viz.; group I: control (normal saline $10 \mathrm{ml} / \mathrm{kg}$, p.o.); group II: indomethacin $(20 \mathrm{mg} / \mathrm{kg} \mathrm{p.o})$; group III: TT-I (50 mg/kg, p.o.); group IV: TT-II (100 mg/kg, p.o.) \& group V: TTIII (200 mg/kg, p.o.).

Rats from each group were placed on the hot plate after drug administration. Then reaction time for the animal to lick the paw or jump from the hot plate was taken as the latency (s). This was repeated at 60 and 90 minutes from the exact time given. The average of the latency was determined from the six rats in each group. The temperature of the hot plate was maintained at $55 \pm 1{ }^{\circ} \mathrm{C}$. The cut off time was kept at 20 seconds.

\section{Anti-inflammatory activity}

\section{Carrageenan-induced hind paw edema}

Inflammation was induced by administering $0.1 \mathrm{ml}$ of (1\%) carrageenan into sub-plantar surface of rat hind paw 20. The animals were divided in to six groups ( $n=6$ each) viz.; group I: carrageenan control (normal saline $10 \mathrm{ml} / \mathrm{kg}$, p.o.); group II: indomethacin $(20 \mathrm{mg} / \mathrm{kg} \mathrm{p.o})$; group III: TT-I (50 mg/kg, p.o.); group IV: TT-II (100 mg/kg, p.o.) \& group V: TT-III (200 mg/kg, p.o.).

In this method, all drugs were given orally. One hour later all animals were injected with $0.1 \mathrm{ml}$ of $1 \%$ Carrageenan solution in the sub-plantar aponeurosis of left hind paw and the paw volume was measured plethysmometrically at $1 \mathrm{hr}, 3 \mathrm{hr}$ and $5 \mathrm{hr}$. Indomethacin $(20 \mathrm{mg} / \mathrm{kg}$, p.o.) as standard and methanolic extract of TT administered by the intragastric route $1 \mathrm{hr}$ before administration of carrageenan.

\section{Safety of drugs on gastric mucosa of rats (ulcer index)}

This method was performed to assess the safety of methanolic extract of TT on the gastric mucosa of rats. In this method, the animals were divided into two groups ( $\mathrm{n}=6$ each) viz.: group I: indomethacin $(20 \mathrm{mg} / \mathrm{kg}$ p.o. $)$ \& group II: TT (200 mg/kg, p.o.).

In the present method, higher doses of drugs were given orally. After 5 hours of administration animals were sacrificed by an overdose of ether vapors. Then the stomachs were removed and opened. The sum of length of lesions was evaluated for ulcer index score $1,2 \& 3$ for erosions $1 \mathrm{~mm}$ or less, $1 \mathrm{~mm}$ to $2 \mathrm{~mm} \&$ more than $2 \mathrm{~mm}$ respectively. The overall score was divided by a factor of 10 and designated as ulcer index ${ }^{21}$.

\section{Statistical analysis}

All the values are expressed as mean \pm S.E.M. The statistical significance was determined by ANOVA followed by Dunnett's test. Values $p<0.05$ was considered as significant. 


\section{RESULTS}

\section{Preliminary Phytochemical Screening}

Alkaloids, Carbohydrates, Cardiac Glycosides, Flavonoids, Saponins, Tannins and Proteins were found to be present in methanolic \& aqueous extract while Steroids were absent in all extracts of TT. Chloroform extracts of TT also showed the presence of Alkaloids.

\section{Analgesic activity}

Effect of methanolic extract of TT fruits on acetic acidinduced writhing in rats

A significant decrease in acetic acid-induced writhing test was observed in $20 \mathrm{~min}$ observation. The score for writhing was significantly decreased by methanolic extract of TT fruits at doses of 50, 100 and $200 \mathrm{mg} / \mathrm{kg}$ on acetic acid-induced writhing in rats over the score of control group $(p<0.05)$. The effect of methanolic extract of TT fruits on acetic acid-induced writhing test was comparable to indomethacin (Table 1).

\section{Effect of methanolic extract of TT fruits on hot plate reaction time in rats}

A significant raise in the reaction time on hot plate was observed at 30,60 and $90 \mathrm{~min}$. In comparison to control group, methanolic extract of TT at doses of 50, 100 and $200 \mathrm{mg} / \mathrm{kg}$ showed a significant increase in the reaction time at 30, 60 and $90 \mathrm{~min}$, respectively $(p<0.05)$. The effect of methanolic extract of TT fruits on reaction time was comparable to the standard drug, indomethacin (Table 2).

Table 1: Effects of methanolic extract of TT fruits on acetic acid-induced writhing in rats

\begin{tabular}{|l|l|l|}
\hline Group & Treatment & $\begin{array}{l}\text { No of writhes } \\
\text { in } 20 \mathrm{~min}\end{array}$ \\
\hline I & Acetic acid control $(10 \mathrm{ml} / \mathrm{kg})$ & $10.50 \pm 0.28$ \\
\hline II & Indomethacin $(20 \mathrm{mg} / \mathrm{kg})$ & $4.00 \pm 0.15^{* * *}$ \\
\hline III & TT-I $(50 \mathrm{mg} / \mathrm{kg})$ & $8.00 \pm 0.34^{* *}$ \\
\hline IV & TT-II $(100 \mathrm{mg} / \mathrm{kg})$ & $6.53 \pm 0.42^{\text {** }}$ \\
\hline V & TT-III $(200 \mathrm{mg} / \mathrm{kg})$ & $4.88 \pm 0.21^{* *}$ \\
\hline
\end{tabular}

${ }^{* *} p<0.01$, compared with acetic acid control, ANOVA followed by Dunnett's test.

\section{Anti-inflammatory activity}

Effect of methanolic extract of TT fruits on carrageenan-induced hind paw edema in rats

The methanolic extract of TT at doses of 50,100 and 200 $\mathrm{mg} / \mathrm{kg}$ showed a significant reduction in the paw volume at $1^{\text {st }}, 3^{\text {rd }}$ and $5^{\text {th }} \mathrm{hr}$ as compared to control group ( $p<$ 0.01). The effect of methanolic extract of TT fruits on paw volume (edema) was comparable to the standard drug, indomethacin (Table 3).

Table 2: Effect of methanolic extract of TT fruits on hot plate reaction time in rats

\begin{tabular}{|c|l|c|c|c|}
\hline \multirow{2}{*}{ Group } & \multicolumn{1}{|c|}{ Treatment } & \multicolumn{3}{|c|}{ Reaction time (s) } \\
\cline { 3 - 5 } & & $30 \mathrm{~min}$ & $60 \mathrm{~min}$ & $90 \mathrm{~min}$ \\
\hline I & Control $(10 \mathrm{ml} / \mathrm{kg})$ & $2.7 \pm 0.21$ & $3.58 \pm 0.27$ & $4.11 \pm 0.44$ \\
\hline II & Indomethacin $(20 \mathrm{mg} / \mathrm{kg})$ & $9.52 \pm 0.32^{* *}$ & $9.65 \pm 0.41^{* *}$ & $9.34 \pm 0.40^{* *}$ \\
\hline III & TT-I $(50 \mathrm{mg} / \mathrm{kg})$ & $3.10 \pm 0.37^{*}$ & $5.55 \pm 0.50^{* *}$ & $6.61 \pm 0.44^{* *}$ \\
\hline IV & TT-II $(100 \mathrm{mg} / \mathrm{kg})$ & $3.50 \pm 0.22^{*}$ & $5.75 \pm 0.30^{*}$ & $7.50 \pm 0.44^{* *}$ \\
\hline V & TT-III $(200 \mathrm{mg} / \mathrm{kg})$ & $4.10 \pm 0.30^{*}$ & $6.54 \pm 0.31^{*}$ & $7.68 \pm 0.35^{* *}$ \\
\hline
\end{tabular}

${ }^{*} p<0.05, * * p<0.01$, compared with control, ANOVA followed by Dunnett's test.

Table 3: Effect of methanolic extract of TT fruits on carrageenan-induced hind paw edema in rats

\begin{tabular}{|c|l|c|c|c|c|}
\hline \multirow{2}{*}{ Group } & Treatment & \multicolumn{3}{|c|}{ Increase in paw volume $(\mathrm{ml}$.$) after carrageenan administration$} \\
\cline { 3 - 6 } & & $0 \mathrm{hr}$ & $1^{\text {st }} \mathrm{hr}$ & $3^{\text {rd }} \mathrm{hr}$ & $5^{\text {th }} \mathrm{hr}$ \\
\hline I & Carrageenan control $(10 \mathrm{mg} / \mathrm{kg})$, & $0.90 \pm 0.02$ & $1.95 \pm 0.03$ & $1.85 \pm 0.03$ & $1.70 \pm 0.03$ \\
\hline II & Indomethacin $(20 \mathrm{mg} / \mathrm{kg})$ & $0.90 \pm 0.2$ & $1.35 \pm 0.05^{* *}$ & $1.00 \pm 0.04^{* *}$ & $1.01 \pm 0.02^{* *}$ \\
\hline III & TT-I $(50 \mathrm{mg} / \mathrm{kg})$ & $0.92 \pm 0.03$ & $1.55 \pm 0.03 * *$ & $1.70 \pm 0.02^{* *}$ & $1.56 \pm 0.02^{* *}$ \\
\hline IV & TT-II $(100 \mathrm{mg} / \mathrm{kg})$ & $0.95 \pm 0.03$ & $1.43 \pm 0.05^{* *}$ & $1.43 \pm 0.02^{* *}$ & $1.41 \pm 0.02^{* *}$ \\
\hline V & TT-III $(200 \mathrm{mg} / \mathrm{kg})$ & $0.92 \pm 0.02$ & $1.37 \pm 0.07^{* *}$ & $1.21 \pm 0.03^{* *}$ & $1.16 \pm 0.03^{* *}$ \\
\hline
\end{tabular}

Values are expressed as mean \pm S.E.M. $(n=6)$,
$*_{p}<0.05, * *_{p}<0.01$, compared with carrageenan control, ANOVA followed by Dunnett's test.

\section{Assessment of the safety of test drugs on gastric mucosa of rats}

This method was adopted to assess the safety of methanolic extract of TT fruits on gastric mucosa of rats using the higher dose of the test drug. In this method the TT $(200 \mathrm{mg} / \mathrm{kg})$ caused no ulcers at all as shown in Table 4.

Table 4: Assessment of the safety of test drugs on gastric mucosa of rats $\left({ }^{n=6}\right)$

\begin{tabular}{|c|l|c|}
\hline \multicolumn{1}{|l|}{ Group } & Treatment & Ulcer index \\
\hline I & Indomethacin $(20 \mathrm{mg} / \mathrm{kg})$ & 4.50 \\
\hline II & TT $(200 \mathrm{mg} / \mathrm{kg})$ & 0 \\
\hline
\end{tabular}

\section{DISCUSSION}

The results of present study are shown in Table 1-4. It indicates that the methanolic extract of TT possesses wound healing potential and the effects are comparable to that of standard. Among the doses, TT $(200 \mathrm{mg} / \mathrm{kg})$ higher dose was found to be more effective than TT $(50 \mathrm{mg} / \mathrm{kg})$ lowest dose.

Inflammation is a pathophysiological response of living tissue to injuries that causes to the local accumulation of plasmic fluid and blood cells, characteristically redness, swelling, pain, and heat. The complex events and mediators concerned in the inflammatory reaction may induce, maintain or aggravate many diseases. However, 
studies have been continuing on inflammatory diseases and the side effects of the currently available antiinflammatory drugs pose a major problem during their clinical uses. Consequently, development of newer and more substantial anti-inflammatory drugs with lesser side effects is necessary ${ }^{22}$.

The abdominal constriction response induced by acetic acid is a sensitive method to establish peripherally acting analgesics ${ }^{19}$. The response is thought to involve local peritoneal receptors. The mean score for writhing was decreased significantly by treatment with methanolic extract of TT.

In hot plate test, nociceptive reaction towards thermal stimuli in rats is a well-established model for detection of opiate analgesic as well as several types of analgesic drugs from spinal origin ${ }^{23}$. A significant increase in the reaction time at various dose levels of methanolic extract of TT fruits $(50,100 \& 200 \mathrm{mg} / \mathrm{kg})$ was observed at $30 \mathrm{~min}, 60$ min and 90 min increased the reaction time in a dose dependent manner which is comparable to indomethacin. These findings suggest that the TT exerts analgesic effect similar to non-steroidal anti-inflammatory drugs. Thus the anti-nociceptive activity shown by TT in methanolic extract on hot plate and acetic acid-induced writhing test might possess centrally and peripherally mediated antinociceptive properties.

Anti-inflammatory agents have broadly been incriminated as one of the important causes of gastritis and gastric ulceration (peptic ulcers). The gastric lesions produced are the result of prostaglandin inhibitory effect of anti-

\section{REFERENCES}

1. Gupta N, Gupta SK, Shukla VK, Singh SP. An Indian Community based epidemiological study of wounds. Journal of Wound Care, 2004 13(8), 323-325.

2. Harshmohan. Text book of Pathology. 5th Ed, New Delhi: JayPee Brothers Medical Publishers Pvt. Ltd. 2005

3. Agarwal PK, Singh A, Gaurav K, Goel S, Khanna HD, Goel RK. Evaluation of wound healing activity of extracts of plantain banana (Musa sapientum var. paradisiaca) in rats. Indian Journal of Experimental Biology, 2009, 47(1), 32-40.

4. Evans P. The healing process at the cellular level. Physiotherapy, 1980, 66(8), 256-259.

5. Handa SS, Kaul MK. Supplement to Cultivation and Utilization of Medicinal Plants, Jammu-Tawi: Regional Research Laboratory. 2006 pp 566.

6. Ansari JA, Inamdar NN. The promise of traditional medicines. International Journal of Pharmacology, 2010, 6(6), 808-812.

7. Ansari JA. Therapeutic approaches in management of drug-induced hepatotoxicity. Journal of Biological Science 2010, 5(10), 386-395.

8. Li SC. Chinese Medicinal Herbs. San Francisco: Georgetown Press. 1983, pp 441.

9. Y.X. Xu, H.S. Chen, H.Q. Liang, Z.B. Gu, W.Y. Lui, W.N. Leung. Three new saponins from Tribulus terrestris. Planta Medica 2000, 66 (6), 545-50.

10. Tutin TG, Heywood VH, Burges NA, Moore DM, Valentine DH, Walters SM. Flora Europaea Volume 2 (Rosaceae to Umbelliferae). Cambridge: University Press. 1968, pp 205.

11. Johnston T. CRC Ethnobotany Desk Reference. Boca Raton, New York, Washington: CRC Press. 1999, pp 844.

12. Suguna L, Chandrakasan G, Joseph KT. Influence of honey on biochemical and biophysical parameters of wounds in rats. Journal of Clinical Biochemistry and Nutrition, 1999, 14(1), 91-99.

13. Sharma SP, Aithal KS, Srinivasan KK, Udupa AL, Kumar V, Kulkarni DR. Antiinflammatory and wound healing activities of crude alcoholic extracts and flavonoids of Vitex leucoxylon. Fitoterapia, 1990, 61(3), 263-265. inflammatory agents, resluted in the cyclo-oxygenase pathway of arachidonic acid metabolism. Prostaglandins generated through cox-1 enzyme pathway have got a gastroprotective role and inhibition of cyclo-oxygenase results in the depletion of both the cox-1 and cox-2 enzymes. In view of this, the drug was investigated for the gastric irritation potential also. The results of the study revealed that no gastric irritation sign was observed with TT administration. Thus, the test drug TT fruits may be considered safer for use as compared to indomethacin, which although having well anti-inflammatory and analgesic activity produces gastric ulcers.

The ability of the methanolic extract of fruits TT to suppress abdominal writhes, increase pain threshold latency, inhibition of the phases of carrageenan-induced inflammation confirms the analgesic and antiinflammatory properties. These findings justify traditional use of this plant in the treatment of pain and other inflammatory conditions and validate its claim of being used for the said purpose in folklore medicine.

\section{CONCLUSION}

It can be concluded that methanolic extract of TT fruits possess wound healing i.e. analgesic and antiinflammatory properties, which are probably mediated via prostaglandin synthesis as well as central inhibitory mechanisms which may be of potential benefit for the management of pain and inflammatory disorders. Although the mechanism of TT involved was not determined in the present study, this is likely to be the focus of another study.

14. Chithra P, Suguna L, Chandrakasan G. Influence of Arginine wound healing in rats. Journal of Clinical Biochemistry and Nutrition, 1995 18(2), 111-117.

15. Shetty S, Udupa S, Udupa L, Somayaji N. Wound healing activity of Ocimum sanctum. Linn with supportive role of anti-oxidant enzymes. Indian Journal of Physiology and Pharmacology, 2006, 50(2), 163-68.

16. Sunil SJ, Agarwal N, Patil MB, Chimkode R, Tripathi A. Antimicrobial and wound healing activities of leaves of Alternanthere sessilis. Linn. International Journal of Green Pharmacy, 2008, 2(3) 141-144.

17. Jamil M, Ansari JA, Ali A, Ahamad J, Ali M, Tamboli E. Pharmacological scientific evidence for the promise of Tribulus terrestris. Int Res J Pharm 2012;3(5):403-406.

18. Trease GE, Evans WC. A Textbook of Pharmacognosy, $15^{\text {th }}$ ed. Saunders Publishers, London 2002, pp. 42-44, 221-415.

19. Turner RA. Analgesics: Screening Methods in Pharmacology. Academic Press, New York. 1965, pp100.

20. Winter CA, Risley EA, Nuss GW. Carrageenan-induced oedemas in hind paw of the rats as an assay for anti-inflammatory drugs. Proceeding of the Society for Experimental Biology and Medicine. 1962, 111, 544-547.

21. Main IHM, Whittle BJR. Investigation of vasodilator and antisecretory role of prostaglandins in the rat gastric mucosa by use of non-steroidal anti-inflammatory drugs. British Journal of Pharmacology. 1975, 53(2), 217-224

22. Su S, Hua Y, Wang Y, Gu W, Zhou W, Duan JA, Jiang H, Chen T, Tang Y. Evaluation of the anti-inflammatory and analgesic properties of individual and combined extracts from Commiphora myrrha, and Boswellia carterii. Journal of Ethnopharmacology 2012, 139(2), 64956.

23. Adzu B, Amos S, Kapu SD, Gamaniel KS. Anti-inflammatory and anti-nociceptive effects of Sphaeranthus senegalensis. Journal of Ethnopharmacology. 2003, 84(2-3), 169-173. 